\title{
Vivências de trabalhadores com diferentes vínculos empregatícios em um laboratório público
}

\author{
Marcia Hespanhol Bernardo 2 , Fábio Frazatto Verde ${ }^{3}$ e Johanna Garrido Pinzón ${ }^{4}$ \\ Pontifícia Universidade Católica de Campinas (Campinas, SP)
}

\begin{abstract}
Este artigo refere-se a uma pesquisa que teve como objetivo analisar a vivência de profissionais com diferentes vínculos empregatícios inseridos em um mesmo serviço público de saúde, tomando como pressuposto que, assim como o setor privado, o setor público também tem sido afetado pelas mudanças no contexto capitalista atual. $\mathrm{O}$ foco da investigação foi um laboratório público, que foi submetido a uma condição de cogestão entre a administração pública e uma entidade sem fins lucrativos, no qual convivem trabalhadores que, apesar de exercerem as mesmas funções, possuem diferentes vínculos empregatícios. Serão discutidas comparativamente as entrevistas realizadas em 2011 com dois profissionais de análises clínicas: um funcionário admitido por concurso público há mais de vinte anos, que foi "militante" do SUS, e outra trabalhadora com vínculo de trabalho terceirizado há três anos, que só atuou no setor privado anteriormente. Observou-se que as vivências de trabalho de ambos são permeadas por características típicas das empresas capitalistas, que se traduzem em precariedade objetiva (baixo salário e vínculo instável), no caso da funcionária terceirizada, e em precariedade subjetiva (sensação de mal-estar com relação ao trabalho), do funcionário público. Apesar dessas diferenças, ambos os trabalhadores, cada um a sua maneira, sofrem com a situação imposta pela ideologia neoliberal que busca terceirizar o serviço público de saúde.
\end{abstract}

Palavras-chave: Saúde mental relacionada ao trabalho, Saúde do trabalhador, Saúde pública, Precarização do trabalho, Desgaste mental no trabalho.

Experiences of workers with different employment relationships in a public laboratory

This research aimed at analyzing the experience of professionals with different employment contracts in the same public health service, assuming that the public sector - similarly to the private sector - has also been affected by changes in the current capitalist context. The focus of the investigation was a public clinical laboratory, which was co-managed by the government and a non-profit organization. There were workers that, despite performing similar functions, had different types of employment contracts. The interviews, conducted in 2011, with two professionals of a laboratory of clinical analysis will be discussed comparatively. The interviewees were a public servant, hired through official examination, who had been employed for more than twenty years, which was an activist for the Unified Health System (SUS), and the other a contract worker, accepted three years prior to the research, who had only worked in the private sector. According to observations, the working experiences of both technicians were permeated by typical features of capitalist enterprises, which are translated into objective precariousness (low salaries and unstable employment), in the case of the contract worker, and subjective precariousness (discontentment in relation to work), in the case of the public servant. Despite these differences, the two workers, each in his/her own manner, were not happy with the situation imposed by the neoliberal ideology that seeks to outsource the public health service.

Keywords: Mental health related to work, Worker's health, Public health, Work precarization, Mental wear down at work.

\section{As novas características da organização do trabalho no setor público}

$\mathrm{O}$ presente artigo surge de uma pesquisa que estudou a vivência de trabalhadores inseridos em um serviço público de saúde, tomando como pressuposto que, assim como o setor privado, o setor público também tem sofrido com as mudanças do contexto capitalista atual.

\footnotetext{
1 Essa pesquisa fez parte de um projeto multicêntrico de âmbito internacional denominado KOFARIPS (o capitalismo organizacional como fator de risco psicossocial), coordenado por Josep Maria Blanch Ribas, da Universidade Autônoma de Barcelona, cujo objetivo foi compreender as repercussões psicossociais do capitalismo organizacional na saúde pública e na universidade pública.
}

2 Docente do Programa de Pós-Graduação Stricto Sensu em Psicologia da PUC-Campinas.

3 Aluno do curso de graduação em Psicologia da PUC-Campinas.

4 Doutoranda do Programa de Pós-Graduação Stricto Sensu em Psicologia da PUC-Campinas. 
Antunes (2005) afirma que a grave crise enfrentada pelo capitalismo a partir da década de 1970 levou a sua reorganização com vistas à retomada do patamar de acumulação e à dominação global. Como consequência, houve a intensificação dos processos de trabalho existentes e a criação de novas formas de relações do trabalho. Ainda que essas transformações tenham se iniciado nas indústrias, elas vêm se expandindo para todos os setores da sociedade, incluindo serviços públicos voltados para as necessidades básicas da população, como os de educação e saúde (Blanch-Ribas \& Cantera, 2011).

Desse modo, cabe mencionar que a divulgação do atual "espírito do capitalismo" (Boltanski \& Chiapello, 1999) foi tão eficiente na afirmação de uma economia de mercado globalizado, que já colonizou quase todos os âmbitos da vida humana individual e coletiva (Blanch-Ribas, 2007). Uma das principais características que marcam o espírito "flexível" do capitalismo atual - presente em praticamente todo o mundo ocidental e, portanto, também no Brasil - diz respeito à reformulação do papel do Estado, que deve estar cada vez mais "enxuto", deixando para o "mercado" o controle e a regulação dos diversos setores que envolvem a sociedade.

Nesse sentido, os estudos dos processos de reforma das instituições da rede pública são particularmente interessantes, já que permitem vislumbrar as tensões, contradições e complementaridades com relação às organizações incluídas na "cultura do novo capitalismo" (Sennett, 2006). Tradicionalmente, as modalidades de especialização do trabalho, os critérios de permanência e mobilidade dos funcionários, assim como o caráter da tradição cultural, refletem a solidez e a estabilidade dos vínculos de trabalho nos serviços de saúde pública, os quais têm se caracterizado por conter disciplinas e profissões vocacionais baseadas em critérios éticos e de valor social. Esses espaços conferiam ao trabalho um estilo de independência e liberdade de exercício das atividades, sem as pressões e a ingerência do "mercado", que são precisamente as diretrizes do new management (Blanch-Ribas, 2007), segundo novos princípios empresariais.

A modificação desse contexto nas últimas décadas em países que tinham sistemas de saúde pública bastante organizados produz a coexistência de lutas e tensões, que envolvem, de um lado, os valores, as identidades, os discursos e as práticas das tradições profissionais do funcionário público e, de outro, as novas formas de gerenciamento flexível (Bauman, 1999; Blanch \& Stecher, 2009; Sennett, 2006).

Mas pode-se indagar quais são as razões para essa mudança e quais suas consequências para a organização do trabalho. Como resposta, Blanch-Ribas e Cantera (2007) afirmam que essa é uma reação ao fato de, nesse início do século XXI, o setor público de numerosos países desenvolvidos ter enfrentado uma crise financeira, agravada pela minimização do papel do Estado na manutenção e na gestão de suas instituições. Procurando sua sustentabilidade, as instituições de saúde pública são, gradualmente, forçadas a fazer parte da lei de oferta e procura, com a adoção da privatização e a tendência a ter de competir com empresas privadas por meio da comercialização de seus respectivos produtos e serviços (Blanch-Ribas \& Cantera, 2011).

Na América Latina, a inserção da lógica capitalista nas instituições públicas se relaciona intimamente com o modelo neoliberal de reforma do Estado desenvolvido pelo Banco Mundial, o qual tem sido implementado desde fins da década de 1980 em diferentes países da região. Especificamente com relação ao setor de saúde, de acordo com Homedes e Ugalde (2005, citado por Blanch-Ribas e Stecher, 2009), esse modelo se organiza em torno dos seguintes princípios:

- A necessidade de cortar o gasto social, por parte dos países latino-americanos, com vistas a um processo de ajuste estrutural promovidos pelo Consenso de Washington ${ }^{5}$ no final da década de 1980;

5 O nome "Consenso de Washington" foi utilizado pelo economista John Williamson em 1989 e refere-se a uma série de políticas econômicas que fizeram parte dos programas do Banco Mundial e do Banco Interamericano de Desenvolvimento, dentre outras 
- A prioridade dos princípios econômicos de lucro, competitividade e benefício próprio sobre os princípios de solidariedade e universalidade no acesso aos serviços de saúde;

- A promoção de uma forte transformação cultural que supõe entender a saúde não como um direito social, mas como um bem. Isso implica estabelecer o consenso de que o lucro no setor de saúde é legítimo e necessário, deixando, assim, que a mercantilização dos serviços de saúde seja a única via para atrair capitais dispostos a desenvolver sistemas de atenção com maior qualidade e eficiência;

- A ideia de que o setor privado sempre será mais eficiente que o público e que, portanto, o Estado não deve se dedicar à criação nem à administração de bens ou serviços, devendo atuar de forma a garantir o livre funcionamento de um mercado no qual distintas empresas concorrem entre si para oferecer um serviço melhor e atrair os consumidores;

- A crença de que a concorrência entre provedores privados leva a um aprimoramento da qualidade e eficiência dos serviços e, consequentemente, a uma maior satisfação dos usuários;

- A descentralização da administração e da gestão dos serviços de saúde;

- A premissa de que a modernização dos serviços públicos exige flexibilização e desregulação das relações de trabalho nesses âmbitos.

Esse fenômeno tem como consequência a implantação de novas formas de organização do trabalho e de vínculos empregatícios no setor público. Observa-se, nesse contexto, a priorização do trabalho individualizado, a subcontratação por meio de empresas terceirizadas e/ou trabalho temporário, novas normas na jornada de trabalho, entre outras formas de exploração do trabalho (Antunes, 2005). Assim, Blanch-Ribas e Cantera (2011) afirmam que o novo tipo de gestão pública...

...reduz instituição de saúde ou universitária, seja qual for sua titularidade (pública, mista ou privada) nas áreas de educação e de saúde ao status de empresa mercantil que compete em igualdade de condições com outras, tratando de vender sua mercadoria de saúde ou de educação em escala local ou global, de acordo com as regras do livre comércio (p. 526).

Nesse contexto, a gerência também assume o papel de cobrar produtividade dos empregados. É assim que se origina a implantação progressiva de um modelo organizacional no setor público, denominado por Blanch-Ribas (2007) como "capitalismo organizacional", o qual toma como base alguns dos princípios que governam o mundo capitalista na atualidade. Esse modelo seria:

desenhado e gerenciado segundo a lógica da economia de mercado, no qual se destacam a retórica da produtividade, eficiência e competitividade; o axioma relativo ao lucro, o individualismo e livre concorrência; a estratégia minimax (maximização dos benefícios do capital e minimização dos custos com pessoal); a política da desregulação das relações de trabalho; a tática de avaliação por resultados em curto prazo (Blanch-Ribas, 2007, p. 15).

O capitalismo organizacional é, assim, um modo específico de gestão "flexível" dos dispositivos de regulação social das relações de trabalho. Tais características não levam em consideração a qualidade dos serviços prestados, e muito menos a qualidade de vida dos trabalhadores, que passam a ser submetidos a um modelo de organização do trabalho muito similar ao do setor privado, com aumento da carga e do ritmo de trabalho, que é medido pela quantidade de serviços prestados. Essa intensificação da pressão por produção e o redirecionamento do sentido do trabalho no setor público evidenciam tensões psicossociais com consequências no nível individual e institucional (Gaulejac, 2007). Nesse contexto, não é difícil concluir que aumenta a relevância das suas consequências psicossociais.

instituições, na época da reorientação econômica da década de 1980. Originalmente, esse pacote de medidas econômicas foi pensado para impulsionar o crescimento dos países da América Latina, mas com os anos se converteu em um programa geral (Moreno, Pérez \& Ruiz, 2004). 
Ainda que a saúde pública no Brasil tenha suas peculiaridades - que serão discutidas mais adiante -, identifica-se, em diversos municípios e estados, que esse processo também está presente. A compreensão dessas dinâmicas nos proporciona uma oportunidade para explorar, no nível psicossocial, as transformações atuais do mundo do trabalho, em particular no âmbito que envolve os servidores públicos.

Considerando essas características, antes de discutir a vivência de trabalhadores no contexto da saúde pública em nosso país, é importante compreender um pouco do histórico do Sistema Único de Saúde (SUS) brasileiro e sua configuração atual.

\section{Capitalismo organizacional no SUS?}

É importante iniciar a apresentação desse tópico lembrando que o SUS brasileiro é relativamente recente, tendo sido criado na Constituição Federal de 1988 e que, antes de sua implementação, a saúde era um direito social restrito aos contribuintes, não disponível a todos. A criação desse sistema foi ambiciosa, ao ponto de abranger desde os atendimentos básicos até os transplantes de órgãos. Além disso, o SUS também está embasado em um conceito ampliado de saúde, segundo o qual o sistema deve abranger, além da atenção ambulatorial e hospitalar, também atividades de prevenção de doenças e de promoção da saúde (Brasil, 1990).

Desde sua criação, o SUS já possuía algumas características marcantes, como o imperativo de que "é dever do Estado garantir saúde" (Brasil, 1988) e o conceito de "seguridade social". O primeiro diz respeito à ideia de contar com políticas sociais e econômicas que visem à redução de risco e outros agravos na relação saúde-doença. Já o segundo conceito tem como objetivo assegurar os direitos relativos à previdência social e à saúde e garantir o atendimento a contribuintes e não contribuintes (Cordeiro, 2004).

Apesar de ter características de um modelo de saúde nacional prioritariamente público, Campos (2006) lembra que a implementação do SUS foi, desde o início, uma reforma incompleta e pouco continuada, pois sempre possuiu problemas marcantes de financiamento e gestão, bem como não conseguiu colocar em prática todos os seus princípios fundamentais, especialmente os que se referem à integralidade, à universalidade e à equidade.

Durante esses mais de vinte anos de existência, o modelo de gerenciamento do SUS foi sendo modificado conforme a conjuntura e o jogo de forças de cada momento histórico. No entanto, um aspecto que deve ser ressaltado é que ele já nasce com a proposta de ser um sistema público que permite a participação "complementar" da iniciativa privada. No parágrafo 1 do artigo 199 da Constituição Federal de 1988, lê-se que "as instituições privadas poderão participar de forma complementar do sistema único de saúde, segundo diretrizes deste, mediante contrato de direito público ou convênio, tendo preferência as entidades filantrópicas e as sem fins lucrativos" (Brasil, 1988).

Desse modo, Santos (2008) afirma que existe "uma tendência histórica do SUS de se conciliar com interesses privados - financeiros, patrimonialistas ou corporativos -, que, se por um lado nos permitiu criar o SUS, por outro lado, tem impedido a cabal construção de um sistema nacional e público de saúde" (p. 1). Campos (2006) também aponta que um dos problemas nacionais está no fato de que defensores do pensamento liberal-privatista exercem constante pressão para a abertura do SUS à iniciativa privada desde sua criação. E, com a expansão da lógica neoliberal descrita acima, intensificou-se essa tendência de incorporação do setor privado no sistema de saúde pública.

Assim, tem-se observado que, cada vez mais, na atualidade, o gerenciamento do SUS, em diversos municípios e estados, está sendo repassado para as chamadas "Organizações Sociais" (OS), que, segundo a Secretaria de Saúde do Estado de São Paulo (2011), seriam entidades privadas que possuem a finalidade de formar parcerias com os governos, assumindo a 
gestão de unidades de saúde. Ou seja, a administração dessas unidades deixa de ser de responsabilidade dos governos e passa para a iniciativa privada.

Nesse contexto, observa-se que vem ocorrendo uma ampla terceirização do gerenciamento dos serviços de saúde em muitos municípios brasileiros. Naqueles em que ainda predomina o gerenciamento público direto, também se observa, muitas vezes, a substituição de uma lógica voltada para a finalidade social por um modelo organizacional capitalista, que prioriza a competição e a produtividade em detrimento da qualidade do serviço realizado, juntamente com a precarização dos vínculos empregatícios.

Podemos compreender que esse processo de privatização é estratégico, pois, no pensamento neoliberal, seria adequado transferir responsabilidades sociais para o setor privado, transformando direitos em produtos e livrando o governo da responsabilidade por esses serviços (Amadigi, Albuquerque, Gonçalves \& Erdmann, 2007). Afinal, de acordo com esses preceitos, garantir os direitos sociais como responsabilidade do Estado é uma forma burocrática de administrar, além de impedir a entrada de capital externo para uma possível modernização (Amadigi et al., 2007). O principal argumento apresentado para defender essa posição é visivelmente alinhado aos preceitos do já citado Consenso de Washington, uma vez que é baseado em dados numéricos que demonstrariam como o SUS é mal administrado pelo Estado (Campos, 2006).

O ex-ministro Luiz Carlos Bresser Pereira, por exemplo, defende que a única forma de garantir qualidade nos serviços de saúde seria por meio de uma saúde privatizada com supervisão pública (Pereira, 1997). Para fazer essa afirmação, apoia-se em ideias frágeis como falta de dinheiro e alta demanda, fundamentadas em uma ideologia cada vez mais fortalecida, de que este seria o único caminho para a modernização da saúde. Entretanto, destrói um valor fundamental conquistado com a implantação do SUS: o direito de todos de ter acesso ao sistema de saúde, conforme assegura a própria Constituição Federal (Brasil, 1988, art. 196).

Essa proposta tem sido alvo de muitas críticas e mobilizações contrárias, que têm obtido algumas vitórias pontuais, mas não têm sido suficientes para impedir que a lógica mercantilista avance e se afirme. Desse modo, tem-se observado que, cada vez mais, governos municipais e estaduais optam por uma administração dividida entre setor público e privado, sendo também a característica do município focalizado na pesquisa apresentada aqui. Esse método administrativo pode criar uma divisão de "classes" dentro no ambiente de trabalho, a partir do estabelecimento de grupos de trabalho marcadamente desiguais (Couto, 2009), como, por exemplo, entre concursados e contratados por empresas/instituições terceirizadas. Vale lembrar que essa estratégia também pode ter a função de impedir a união de trabalhadores para reivindicações de melhorias nas condições de trabalho.

Tais circunstâncias têm impactos tanto na qualidade dos serviços prestados como na saúde e bem-estar dos profissionais envolvidos. Considerando este cenário, indaga-se se a vivência de diferentes tipos de relação de trabalho (concursado ou contratado por meio de terceirização da gestão) pode ter consequências para o bem-estar e para a saúde dos trabalhadores da saúde pública.

Tendo em vista o que foi apresentado até aqui, o presente artigo visa a expor os resultados de uma pesquisa na qual se buscou estudar a vivência de profissionais com diferentes vínculos empregatícios inseridos em um mesmo serviço público de saúde, tomando como pressuposto que, assim como o setor privado, o setor público também tem sido afetado pelas mudanças no contexto capitalista atual.

Para a pesquisa, utilizou-se como referencial teórico a concepção de precariedade subjetiva proposta por Linhart (2009) e a ideia de desgaste mental sugerida por SeligmannSilva (2011), que serão apresentadas sucintamente a seguir. 


\title{
As formas de precariedade no trabalho no contexto atual e o desgaste mental
}

Pode-se dizer que a principal característica da forma de organização do trabalho contemporâneo é a "flexibilidade" (Bernardo, 2009). Essa noção abrange um conjunto de características, entre as quais pode-se destacar a necessidade de os trabalhadores serem capazes de exercer uma variedade maior de tarefas; a desregulamentação das jornadas de trabalho, com banco de horas, por exemplo; a busca de um maior envolvimento do trabalhador com a "missão" da empresa; a individualização das relações de trabalho por meio de avaliações individuais etc. Assim, cabe mencionar que a transformação do contexto capitalista modifica também o tipo de trabalhador requerido na atualidade e cria novas condições subjetivas de trabalho.

Entre as características mais influentes e categóricas do contexto contemporâneo está o controle subjetivo sobre o trabalhador, tal como define Linhart:

\begin{abstract}
Trata-se de uma evolução central e determinante. A empresa moderna pretende ser uma empresa de indivíduos com os quais ela pode estabelecer relações de confiança. Ela reivindica a confiança dos assalariados e quer também poder confiar neles. Todas as políticas empresariais de modernização têm por objetivo uma empresa constituída, sobretudo, por indivíduos cujas relações com a hierarquia e os colegas sejam claramente estabelecidas em função das necessidades da organização e da eficácia das atividades, que, por sua natureza, escapam ao controle e não são passíveis de condução pela hierarquia (2000, p. 27).
\end{abstract}

Assim, observa-se que, ainda que grande parte dos trabalhadores atuais esteja submetida a condições de trabalho objetivamente precárias, que envolvem, por exemplo, o trabalho terceirizado, temporário ou informal (Franco, Druck \& Seligmann-Silva, 2010), também existe aquilo que Linhart (2009) chama de "precariedade subjetiva". Essa noção diz respeito a um "sentimento de precariedade que podem ter assalariados estáveis confrontados com exigências cada vez maiores em seu trabalho e que estão permanentemente preocupados com a ideia de nem sempre estarem em condições de responder a elas" (Linhart, 2009, p. 1). A precariedade subjetiva se caracteriza, assim, pelo "sentimento de isolamento e abandono" e, de acordo com a autora, "não é estranha ao sofrimento que se inscreve cada vez mais na relação com o trabalho moderno; seria, inclusive, uma de suas características" (p. 3).

Esse conceito está intimamente relacionado com as diversas estratégias e imposições trazidas pelas novas formas de organização do trabalho que têm como objetivo manter os trabalhadores em suspense, propiciando-lhes uma tensão que, nessa concepção, seria altamente produtiva. Tal como o assinala Linhart (2009), o segredo para tornar os trabalhadores mais adaptáveis nestes tempos do trabalho "flexível" está em mantê-los, permanentemente, em um estado de insegurança, obrigando-os a trabalhar no limite de suas possibilidades, sempre na procura de se superar:

\footnotetext{
Vislumbra-se então a virtude da desestabilização, da precarização no trabalho que impõe ao assalariado demonstrar o tempo todo suas capacidades e ser validado permanentemente. A mobilidade, a avaliação sistemática e o isolamento constituem (ao lado da tensão permanente entre objetivos difíceis de conciliar) fatores de vulnerabilidade, de fragilização, fontes também de sofrimento. São as formas que adquire a precarização dos assalariados "estáveis" (Linhart, 2009, p. 12).
}

Considerando essas características, o que se pode dizer das consequências para a saúde mental dos trabalhadores? Sato e Bernardo (2005) fazem referência ao vínculo existente entre esse aspecto e a organização do trabalho, assinalando que a pressão pela produção, a falta de autonomia pelo controle excessivo no trabalho, o ritmo acelerado, a sobrecarga de 
responsabilidades, a ameaça do desemprego e o aumento da competitividade estão estreitamente relacionados com os sintomas de ordem psíquica.

Por sua parte, Gaulejac (2007) afirma que a reestruturação produtiva traz a retórica da excelência como um imperativo exigido no desempenho dos empregados, a qual gerou "a neurose de excelência" e outras consequências psicopatológicas distintas resultantes da intensificação do trabalho, como a depressão, o esgotamento profissional (Burnout), o estresse e a adição ao trabalho (work addicts).

Da mesma forma, Franco, Druck e Seligmann-Silva (2010) mencionam a identificação de um conjunto de transtornos mentais relacionados ao desgaste pelo trabalho, entre os quais se encontram: estresse, depressão, esgotamento profissional (Burnout), estresse pós-traumático (TEPT) e a dependência de bebidas alcoólicas e outras substâncias psicoativas.

Seligmann-Silva (2011) afirma que os processos no trabalho podem gerar um "desgaste mental", que pode iniciar-se com uma vivência de sofrimento psíquico, atingindo, depois, tanto aspectos psicoafetivos como cognitivos e orgânicos. A noção de desgaste foi apresentada inicialmente por Laurell e Noriega (1989), que, partindo de uma compreensão marxista do processo saúde-doença, defendem que a relação saúde-doença no trabalho deve ser compreendida no interior das relações de produção capitalistas. Mantendo a coerência com esses pressupostos, Seligmann-Silva (2011) defende que o desgaste mental no trabalho se dá na forma de um processo constituído de "experiências que se constroem, diacronicamente, ao longo das experiências de vida laboral e extralaboral dos indivíduos" (Seligmann-Silva, 2011, p. 142). Trata-se, assim, de uma perspectiva teórica de caráter integrador, que parte da ideia de que, para compreender a relação saúde-trabalho, deve-se sempre considerar o contexto sóciohistórico que a determina.

Dessa forma, é possível verificar como os conceitos de "precariedade subjetiva", desenvolvido por Linhart (2009), e o de "desgaste mental", proposto por Seligmann-Silva (2011), podem ser complementares, ajudando a compreender a vivência de trabalhadores dos serviços públicos submetidos à lógica do capitalismo organizacional, conforme será apresentado a seguir.

\section{Abordando o problema}

O tipo de delineamento adotado nesta pesquisa teve caráter qualitativo, com a realização de entrevistas em profundidade, que ocorreram no final de 2010. Apesar de se contar com um roteiro norteador, as entrevistas foram conduzidas da maneira mais informal possível, de modo a deixar os entrevistados à vontade e buscando não induzir respostas ou vocabulário específico.

Buscaram-se possíveis sujeitos da pesquisa em um hospital público de um município do interior paulista, que funcionava em sistema de cogestão com o setor privado. Os trabalhadores desse hospital eram divididos em dois diferentes tipos de contratos de trabalho: os estatutários, que ingressaram por meio de concursos públicos, e os contratados por uma entidade privada, que admite funcionários pelas normas da Consolidação das Leis do Trabalho (CLT) ${ }^{6}$ para diversos serviços públicos de saúde no município. Apesar de exercerem as mesmas funções, esses trabalhadores estão submetidos a relações de trabalho bastante contrastantes, que envolvem, entre outras coisas, estabilidade no emprego, diferentes carreiras, salários e benefícios.

6 A CLT rege os contratos de trabalho no setor privado. 
Inicialmente, pretendia-se entrevistar trabalhadores do setor de enfermagem do hospital, por estarem diretamente envolvidos no atendimento ao público. No entanto, no período em que a pesquisa foi realizada, não havia mais funcionários públicos nesse setor (todos tinham sido transferidos para outras unidades de saúde), restando apenas profissionais contratados pela entidade privada. $\mathrm{O}$ mesmo ocorria em diversos outros setores.

Sendo assim, buscou-se algum setor do hospital em que se encontrassem profissionais das duas categorias empregatícias e verificou-se que o laboratório de análises clínicas atendia a essa condição, contando com profissionais com os dois tipos de vínculos trabalhando nas mesmas equipes e com idênticas atribuições. Nesse laboratório, também chamou a atenção o fato de todos os trabalhadores, independentemente do vínculo empregatício, estarem sujeitos a metas de produção, que eram estabelecidas para a equipe, e não individualmente.

Este artigo focaliza especificamente as entrevistas de dois analistas clínicos, tendo em vista o contraste observado entre elas: um funcionário público concursado, que será referido como Edu, e outra com vínculo CLT, contratada pela entidade privada parceira na gestão do hospital, que será denominada aqui como Bia. O primeiro é um homem de 42 anos de idade, com formação de técnico de laboratório, que trabalhava como servidor público havia vinte anos, sendo nove no município onde está o hospital. Durante boa parte desse tempo, foi militante político e participava ativamente de ações sociais em defesa do SUS.

A outra analista clínica participante da pesquisa era uma bióloga de 40 anos, com três anos de trabalho com vínculo terceirizado no laboratório focalizado na pesquisa. $\mathrm{Na}$ ocasião da entrevista, ela acumulava treze anos de experiência na área de análise clínica, sendo que seus vínculos anteriores foram com laboratórios exclusivamente privados.

As entrevistas foram gravadas, transcritas e submetidas a análise de conteúdo (Bardin, 1977), que possibilitou destacar as duas categorias que serão discutidas a seguir.

\section{Implicações do processo de terceirização na vivência de trabalhadores da saúde pública}

Ao analisar as entrevistas realizadas, duas categorias se destacaram: a) aspectos do processo de terceirização; e b) precariedade, desgaste e o adoecimento do trabalhador. Entretanto, deve-se lembrar que, por dizerem respeito ao mesmo contexto de trabalho, essas categorias estão intimamente relacionadas e, muitas vezes, se sobrepõem. Antes de discutir cada uma delas, porém, é importante descrever algumas características da organização do trabalho no laboratório.

\section{Algumas características da organização do trabalho dos entrevistados}

O laboratório de análises clínicas onde trabalhavam os dois entrevistados é responsável pela realização de todos os exames laboratoriais (sangue, fezes, urina, patologias específicas) solicitados pelas unidades de saúde pública do município. A tarefa dos profissionais que ali atuam é, fundamentalmente, analisar e liberar resultados de exames realizados em equipamentos automáticos, mas há alguns que devem ser conduzidos manualmente. As falas dos entrevistados indicam que o processo de trabalho é organizado em diversos setores de acordo com os tipos de exames realizados. Nesses setores, trabalham equipes de oito a nove funcionários de ambos os vínculos contratuais (funcionário público ou CLT).

Cada setor também possui um funcionário, geralmente um técnico de laboratório, responsável pela sala e pela supervisão da equipe de trabalho. Segundo ambos os entrevistados, 
o tipo de vínculo empregatício não influencia essa escolha. Além disso, o responsável por cada sala não possui um poder direto sobre os colegas e também não recebe nenhum adicional salarial para exercer essa função. Suas atribuições se limitam a relatar o que não está funcionando na equipe ou pedir materiais extras.

Os tipos de vínculos empregatícios também não têm nenhuma influência sobre a definição das atribuições dos analistas clínicos do laboratório. Assim, dois funcionários com diferentes contratos fazem exatamente as mesmas coisas. Entretanto, do ponto de vista trabalhista, os funcionários públicos possuem alguns benefícios que os outros não têm, conforme será discutido mais adiante.

\title{
A terceirização como uma forma de precarização do trabalho público
}

Como foi discutido na introdução, vivenciamos um momento histórico no qual é perceptível a influência da ideologia neoliberal no contexto do trabalho público (Blanch-Ribas \& Cantera, 2011). E foi justamente esse pressuposto um dos pontos mais marcados nas entrevistas. Nas falas dos dois entrevistados, pode-se notar como o processo de terceirização pelo qual o laboratório estava passando se reflete diretamente nas condições e relações do trabalho.

A própria convivência de pessoas com diferentes contratos de trabalho e, consequentemente, com diferentes direitos e condições salariais é uma demonstração dessa lógica. Segundo Bia, enquanto o funcionário terceirizado trabalha 40 horas semanais e só recebe cesta básica simples além de seu salário, o colega com vínculo público, que trabalha ao seu lado e exerce exatamente nas mesmas funções, possui estabilidade de emprego, trabalha 36 horas semanais, recebe vale-alimentação e tem um salário que é quase o dobro dos colegas com vínculo terceirizado. Podemos notar alguns desses aspectos no seguinte recorte da fala de Bia:

Então eles [funcionários concursados] ganham quase o dobro, e a gente faz exatamente a mesma coisa, sentada na mesma bancada. Eu sento aqui e libero exame, eles liberam os mesmo exames do meu lado, a gente faz exatamente as mesmas coisas, só que tem salário diferente ou, por exemplo, eu ganho a cesta básica, ela é boa, mas é simplesinha, e eles ganham vale de quinhentos e poucos reais pra fazer compra.

Outro aspecto destacado pelos entrevistados, que corrobora a afirmação de BlanchRibas e Cantera (2011) de que o setor público vem cada vez mais incorporando uma ideologia de gestão empresarial diz respeito à valorização da produtividade, que, de acordo com Edu, transforma o laboratório em fábrica. Observa-se no relato desse entrevistado como esse fato afeta diretamente o ambiente de trabalho:

\begin{abstract}
Bem, quando você transforma uma unidade de saúde em fábrica, as relações passam a diminuir e até a inexistir. Você não tem tempo pra olhar pro seu colega, você tem uma produção, no final do dia tem que entregar aquela produção. Então, você tem menos tempo pra socializar, né? E isso é péssimo, e isso aqui é o grande "tcham". [pesquisador: e o que pode estar melhorando nesse tipo de relação?...] (silêncio)... Difícil, viu, encontrar uma melhora, porque as pessoas se estressam mais... elas adoecem mais e... existe uma cobrança constante de produção. Então, eu não vejo melhora, eu vejo só piora.
\end{abstract}

Interessante observar que referir-se às características geradas pelo processo de terceirização como "o grande tcham" administrativo, como faz Edu, cria a ideia de algo realmente planejado, como se a intenção fosse diminuir as relações sociais no ambiente de trabalho.

Além desse aspecto, ambos os entrevistados pontuam como tal contexto de diferenças de vínculos (cogestão) e até diferenças hierárquicas possibilitam um velado "assédio moral" (Edu) ou "muitas fofocas" (Bia), que seria "um dos piores problemas no ambiente de trabalho" 
(Bia). Mas, ao falar das fofocas, Bia focaliza o problema no plano individual, como se pode observar no seguinte trecho de sua fala:

Então esse negócio de ficar fazendo fofoca do tipo: "eu fiz isso, o outro não fez" sabe? "Eu li tantos tubos hoje, o outro não leu","ai porque eu faço mais que o outro". Então esse tipo de coisa "a o outro tem mais regalia que eu", parece criança, esse tipo de coisa eu não gosto não. Mas é dos dois lados, depende de cada um. Então, fica muito complicado, às vezes, até a própria convivência, né? Então tem pessoas que pedem pra mudar de setor, na Prefeitura isso é muito comum (Bia).

Edu, por outro lado, identifica a fonte do problema na gestão:

E a gestão como um todo [é a responsável]. Então, como a instituição passou a ser uma instituição produtora, fabriqueta, e o serviço público também está com essa visão particular, aqui, muitas vezes, tem [também] essa visão de laboratório particular, né? Então fica um certo assédio, "olha, fulano não produziu tanto quanto sicrano".

Apesar de, inicialmente, nenhum dos entrevistados associar a existência dessas fofocas e assédios com o tipo de vínculo empregatício, ao serem indagados diretamente sobre isso, as respostas são diferentes. Para Bia, realmente não há ligação com os tipos de vínculo e existe dos "dois lados". Enquanto Edu respondeu que esse problema "existe de pessoa pra pessoa e existe também de vínculo pra vínculo. Por exemplo, um diz assim: "Ah! Você é funcionário terceirizado, você nem tem vínculo, amanhã você tá na rua...”.

A maior queixa dos entrevistados foi justamente a presença, no contexto de trabalho, de características que indicam que o "capitalismo organizacional" (Blanch-Ribas, 2007) já faz parte do cotidiano no laboratório. Segundo Edu, o ambiente de trabalho no laboratório se transformou em "uma fabriqueta de alta produção", na qual cada um realiza mais de mil exames por dia. Nas falas desse mesmo trabalhador, nota-se como a necessidade contínua de produção modificou negativamente as relações interpessoais no ambiente de trabalho de uma forma similar à destacada por Linhart (2009). Ele ressalta que, atualmente, todos trabalham de forma cada vez mais individualizada. Ainda, segundo Edu, com a atenção toda voltada para a cota de exames diários que precisam ser realizados e liberados, não há tempo para conhecer de forma mais profunda o colega que trabalha na mesma equipe e, às vezes, bem ao seu lado na mesma bancada.

Já Bia, apesar de também criticar o modelo de cogestão, destaca o fato de estar em uma situação melhor do que nos laboratórios privados em que trabalhou anteriormente. Diz ela: "E mesmo assim [na situação desfavorável relativa aos funcionários concursados] aqui dentro, eu ganho muito melhor do que se eu trabalhasse em um trabalho particular. Eu ganharia menos da metade, pra fazer exatamente o que eu faço aqui ou mais".

Portanto, fica evidente o fato de Bia sentir um progresso na sua carreira profissional, pois, apesar da diferença com relação aos colegas concursados, está melhor do que se estivesse em uma instituição totalmente privada. No entanto, apesar dessas diferenças, observa-se que a história de cada um dos entrevistados é marcada por um processo de precarização específico, que tem consequências para seu bem-estar e para sua saúde, conforme será discutido a seguir.

\section{Precariedade, desgaste e o adoecimento do trabalhador}

A terceirização da contratação de trabalhadores nos serviços públicos, em geral, está associada à precarização das relações (e, às vezes, também das condições) de trabalho, que pode ser observada de formas diferentes no caso de Bia e de Edu. Apesar de Bia realizar exatamente o mesmo trabalho de Edu, ela não tem os benefícios nem a estabilidade no emprego que ele possui. Contudo, isso não quer dizer que Edu também não vivencie uma situação de 
precariedade. No seu caso, ela se dá menos no plano objetivo e mais no subjetivo, pois envolve a própria relação de Edu com anos de serviço público.

Nesse sentido, a noção de "precariedade subjetiva" apresentada por Linhart (2009) é bastante interessante para compreender a vivência de Edu. $O$ caso dele evidencia como esse tipo de precariedade está diretamente associada ao modelo administrativo do trabalho e tem como característica o desgaste mental (Seligmann-Silva, 2011). Assim, ao narrar sua história na saúde pública e sua vivência atual, Edu denuncia também o sofrimento decorrente:

Esse processo me faz assim: como é um processo que me incomoda bastante, eu acabo tendo que fingir que ele não existe, então muitas das coisas que é e que acabam sendo acarretadas por causa disso, eu finjo que não existe. Entendeu? Eu finjo que não tô vendo, e acaba que eu me sinto irresponsável às vezes. É lógico que eu, no final das contas, falo: não... Não tô sendo irresponsável... Mas me dá esse sentimento, né? E acaba mexendo na minha saúde. Acaba mexendo... e como eu sou hipertenso, acaba afetando, né? (Edu).

O sentimento de ser "irresponsável" pode ser compreendido pelo fato de Edu ter sido militante pela construção do SUS em boa parte dos vinte anos de trabalho na saúde pública e, hoje, buscar se afastar dessas lutas para preservar a própria saúde:

Olha... Já fui muito político, já participei de conselho, de grupo, de CIPA [Comissão Interna de Prevenção de Acidentes], de biossegurança... Hoje, neste momento, estou exaurido, estou exausto psicologicamente, né? Estou exausto de tudo isso e tô fugindo loucamente de tudo isso. Toda vez que falam assim: "tem uma movimentação, tem uma luta, tem uma reunião...”. Eu passo do outro lado da calçada, de tão exausto que estou.

Sua vivência atual também parece roubar-lhe a possibilidade de exercer seu trabalho com o prazer de quem faz algo pelo outro. Apesar de ainda reconhecer a importância da sua atividade, Edu fala da crescente dificuldade para fazer um trabalho de boa qualidade, na medida em que o que importa cada vez mais é a "produtividade". Queixa-se que, mesmo quando se fala em qualidade, o que está em jogo é apenas a busca de uma certificação de uma entidade privada, que implica mais burocracia do que a melhora da atividade-fim. Assim, afirma ele:

A transformação do laboratório em fabriqueta acaba afetando, porque assim o meu trabalho não pode ser desenvolvido... e cada tarefa que eu executo eu tenho que fazer dez mil papéis, dez mil ações antes de executar o meu trabalho. E isso é estressante, isso é irritante e, muitas vezes, desnecessário. E com a proposta final que eu discordo plenamente, porque eu entendo que o poder público tá na ponta, e não no meio. Então, isso é estressante e acaba, às vezes, atrapalhando a rotina.

Além de ter o trabalho prejudicado pelo processo burocrático, Edu também sofre por ter de colaborar com um modelo de trabalho que, para ele, não tem sentido e com o qual não concorda. Para entender melhor todo esse processo passado por Edu, podemos nos apoiar na ideia de desgaste mental, apresentada por Seligmann-Silva (2011), segundo a qual "é possível reconhecer, nas trajetórias humanas de vida e de trabalho, muitas vezes, um outro consumo: aquele que corrói a identidade, ao atingir valores e crenças, podendo inclusive ferir a dignidade e a esperança" (p. 143). A partir dessa definição, a autora destaca que a abordagem psicossomática já demonstrou que afetos e emoções são vivenciados e experenciados corporalmente. Edu também descreve como começou a sentir no próprio corpo as consequências de ter se chocado com a gestão do ambiente de trabalho e com a própria gestão municipal:

É porque é assim, aqui especialmente eu comecei muito engajado, né? Em melhorias políticas, e acabei me... como que chama... me chocando com a gestão daqui, pesado, a ponto de interferir na minha casa, de eu adoecer, pressão alta, tendinite [...] Eu tentei uma, tentei duas, tentei três e vi que eu ia me danar, né? [...] Aí eu adoeci. E adoeci assim, primeiro eu adoeci psicologicamente e aí isso refletiu fisicamente. Comecei a ter a pressão 
alta, comecei a ter uma relação familiar péssima, e fiquei doente. E [ouvia de] amigos, de profissional: "Não cara, você não é assim, vai lá, você não era assim". Aí, eu fui ao médico e o doutor disse: "Não, você não tem nada de verdade. De verdade, o que você tem é: você precisa mudar sua cabeça que você melhora. O que você está tendo no físico é o que no, seu psicológico, está abalado". Então, isso durou dois anos e pouco [...] e ainda estou me curando. E, aí, eu decidi virar as costas pra tudo isso e continuar trabalhando.

Observa-se como essa fala de Edu descreve o processo de desgaste mental (SeligmannSilva, 2011) pelo qual ele vinha passando. Parece que ele realmente perde parte de si como resultado do atrito de suas ideias com as da gestão que se baseia na ideia de terceirização do serviço público.

Por outro lado, se Edu sofre com esse processo de precariedade subjetiva no espaço de trabalho e no contexto de mudanças de gestão, Bia sofre uma precariedade objetiva relativa ao seu vínculo de trabalho. Todavia, curiosamente, essa vivência não parece afetá-la tão fortemente como ocorre com Edu. Tal constatação parece se explicar pelo fato de Bia não possuir a mesma ligação ideológica com a saúde pública. Para ela, esse é apenas mais um trabalho:
...porque meu objetivo sempre foi chegar, realizar meu trabalho e ir embora. Porque, no meu ponto de vista, eu gosto do que eu faço, mas minha vida não é só o que eu faço profissionalmente, eu tenho uma outra vida lá fora também. Então, eu tento partir do princípio prático de qual é a função? É essa a função? Eu gosto de fazer isso aqui. Eu faço da melhor maneira possível, da melhor maneira que eu posso mesmo, eu faço. Cumpro minha obrigação e vou embora. Quando chego na minha casa, eu não fico pensando no que tá aqui, porque, se eu fiz bem feito, não tem por que eu ficar pensando. E eu tenho minha vida pessoal. Tem umas pessoas que vivem o trabalho, entendeu?

Todavia, sua fala indica que a situação precária com relação aos colegas concursados também gera uma insatisfação que pode se configurar como um processo desgaste, ainda que menos intenso do que aquele referido por Edu. Esse desgaste pode ocorrer em decorrência das diferenças claras de seu contrato de trabalho com relação aos dos colegas de equipe com vínculo público. Por exemplo, ao falar das cargas de trabalho, nota-se uma nítida comparação de si com os colegas:

Eles fazem... são 6 dias e 6 horas, são 36 horas. A gente é 40 horas. É pouca diferença, mas tem. Então, na realidade, eles trabalham 6 horas por dia, e tem um dia que eles dobram pra não vir no sábado, porque o laboratório não tá funcionando no sábado. Eles têm que cumprir aquela carga horária, eles fazem doze horas um dia na semana e é tudo bem organizado por setor. Enfim, eles têm as férias e, depois, eles têm licença-prêmio ${ }^{7}$ quando não faltam.

Em outro momento, Bia fala sobre a diferença de pressão sofrida pelas pessoas com vínculos distintos, que evidencia a precariedade dos trabalhadores terceirizados:

Esse funcionário (vínculo CLT) não tem nenhum tipo de estabilidade, ele ganha menos que funcionário da Prefeitura pra fazer o mesmo serviço dentro da sala. É o mesmo cargo, o mesmo serviço, mas ganha menos porque o contrato é diferente. Ele tem que tomar mais cuidado com algumas coisas, ele tem que estar sempre atento aos horários dele e às obrigações, porque, se as coisas não ocorrem como eles esperam, eles mandam a pessoa embora. Então, tem um tratamento diferente, sim, de um pro outro.

Outra situação descrita por Bia diz respeito às formas diferentes de advertir funcionários que não estão cumprindo suas obrigações:

7 Trata-se de um benefício do servidor público de algumas administrações que confere àqueles que não atingirem um número máximo de faltas o direito de ter três meses de folga a cada cinco anos. 
É, na realidade, por exemplo, se você está ali em uma equipe e aquele funcionário da Prefeitura saiu, por exemplo, aí tem uma reclamação na sala. A reclamação é levada até a chefia, "pô, o cara some o dia inteiro... não sei o quê...". Aí, chama atenção, conversa com o funcionário, entendeu? Às vezes, emenda, às vezes não, mas é por conta dele. Agora, quando é o funcionário contratado [terceirizado], ele vai falar assim: "olha, você se emenda, eu vou te dar uma advertência por escrito e, depois, eu vou mandar um comunicado, do tipo assim, gostaria de afastá-lo...” (risos).

Com experiência no setor privado, Bia sempre conviveu com essa necessidade de adaptar-se ao trabalho. E é importante notar que a constante adaptação à precariedade objetiva do mundo do trabalho, vivenciada pela funcionária terceirizada, também tem efeitos sobre sua subjetividade. Esse aspecto é abordado por ela no momento em que compara os objetivos idealizados na época de recém-formada com a vivência real das relações no trabalho:

Porque é assim: quando você sai da faculdade, você fala assim: "vou virar esse mundo, vou fazer esse negócio girar de outro jeito", mas, aí, você começa a olhar... entendeu? É... porque você começa a levar umas bordoadas também. É assim: "não tá bom pra você? Próximo!" (risos) Entendeu? E você também precisa sobreviver nesse mundo todo, nessa doidera.

Bia também se manifestou conformada com o atual contrato de emprego e com a diferença em relação aos colegas concursados, pois está em condição melhor do que no serviço privado, no qual trabalhava anteriormente:

Mas veja bem, eles são concursados, e no contrato deles já regia tudo isso, entendeu? E quando eu fui contratada [...], no meu contrato, já regia também tudo o que eu ganho, tudo certinho. E mesmo assim [...], eu ganho muito melhor do que se eu trabalhasse em um trabalho particular. Eu ganharia menos da metade, pra fazer exatamente o que eu faço aqui ou mais.

Nota-se, assim, que ela parece ter adotado uma postura pragmática e fatalista ${ }^{8}$ (MartínBaró, 2006), como que admitindo sua impossibilidade de lutar contra um sistema mais forte.

Observa-se, portanto, que as vivências de trabalho de ambos os entrevistados são permeadas por características típicas das empresas capitalistas, demonstrando como o capitalismo organizacional (Blanch-Ribas, 2007) está presente no contexto pesquisado. Tal situação se traduz em precariedade objetiva para Bia e subjetiva para Edu. As cargas de trabalho inerentes a esse contexto, seja na vivência de um ou de outro, parecem levar ao desgaste mental (Seligmann-Silva, 2011). Dessa forma, poderíamos indagar até que ponto pode a lógica capitalista ingressar na saúde pública? O que pode ocorrer, em curto e longo prazo, com trabalhadores que apresentam um desgaste mental que se relaciona diretamente a esse tipo de contexto de trabalho?

Para responder a essas questões, não é necessário muito esforço, pois, ao pensar que esses trabalhadores vivenciam uma situação de sofrimento psicológico, o próximo passo é o aparecimento de adoecimento físico e/ou mental. E esse adoecimento é resultado justamente do fato de a precarização passar a ser atributo central nas novas formas de relação de trabalho (Franco et al., 2010).

O caminho do sofrimento psicológico ao adoecimento físico pode ser exemplificado pelo caso de Edu, que relaciona seus problemas de saúde diretamente a sua situação de trabalho. Depois de falar de sua decepção com o atual contexto de trabalho, ele relata os efeitos dessa vivência sobre sua saúde:

8 Fatalismo, aqui, seria uma ideologização da realidade e que resulta no processo de considerar natural uma situação construída e determinada por uma ideologia dominante. 
Primeiro, eu estava me enxergando como um mal profissional, e isso me adoeceu. Quando eu comecei a enxergar que sou um mal profissional? Será que eu sou um mal profissional? Será que eu sou? Aí,eu adoeci. E adoeci assim, primeiro eu adoeci psicologicamente e isso refletiu fisicamente.

\section{Considerações Finais}

Embora as referências ao adoecimento tenham surgido claramente na fala de Edu, a entrevistada Bia não explicitou essa vivência, referindo-se a uma postura pragmática com sua situação de precariedade com relação aos colegas concursados. Edu teve um grande envolvimento ideológico com o projeto do SUS como um sistema de saúde verdadeiramente público e, por isso, sofre ao ver tal projeto sendo corroído pelo ideário neoliberal. Já Bia percebe a injustiça das diferenças de vínculos empregatícios e até a lógica da produtividade, mas parece ver essa situação como algo natural, não passível de modificação e, assim, busca adotar um comportamento adaptativo, distanciando-se afetivamente do trabalho.

Interessante observar que essa constatação contraria as expectativas iniciais da pesquisa de que a vivência dos trabalhadores terceirizados fosse permeada por desgaste mental maior do que a dos funcionários concursados. Entretanto, apesar dessas diferenças de envolvimento e/ou sofrimento no trabalho, as entrevistas indicam que ambos os trabalhadores, cada um a sua maneira, sofrem com a situação imposta pela ideologia neoliberal que busca terceirizar o serviço público de saúde do município.

Apesar da evidente limitação da possibilidade de generalização dos resultados desta discussão, que considerou apenas dois casos, ela permite evidenciar diferentes aspectos da lógica que vem cada vez mais ocupando a saúde pública e que afetam diretamente a vida e a saúde dos trabalhadores e, possivelmente, também da população atendida.

\section{Referências}

Amadigi, F. R., Albuquerque, G. L., Gonçalves, E. R. \& Erdmann, A. L. (2007). A relação público-privado na saúde brasileira: refletindo eticamente sobre os impasses e tendências para o SUS. Ciência, Cuidado e Saúde, 6 (4), 508-513.

Antunes, R. (2005). Los sentidos del trabajo: ensayos sobre la afirmación y la negación del trabajo. Buenos Aires: Herramienta Ediciones.

Bardin, L. (1977). Análise de conteúdo. Lisboa: Edições 70.

Bauman, Z. (1999). La globalización: consecuencias humanas. Cidade do México: Fondo de Cultura Económica.

Bernardo, M. H. (2009). Flexibilização do discurso de gestão como estratégia para legitimar o poder empresarial na era do toyotismo: uma discussão a partir da vivência de trabalhadores. Cadernos de Psicologia Social do Trabalho, 12 (1), 93-109.

Blanch-Ribas, J. M. (Org.) (2007). El capitalismo organizacional como factor de riesgo psicosocial: efectos psicológicos colaterales de las nuevas condiciones de trabajo dictadas por el capitalismo académico y sanitario implantado en universidades y hospitales no lucrativos de la red pública. Ministerio Educación y Ciência de España.

Blanch-Ribas, J. M. \& Cantera, L. (2007). El capitalismo sanitario como factor de riesgo psicosocial. In C. Guillén \& R. Guil (Eds.), Psicología social: un encuentro de perspectivas (vol. 1, pp. 1075-1080). Cádiz: APPS.

Blanch-Ribas, J. M. \& Cantera, L. (2011). La nueva gestión pública de universidades y hospitales: aplicaciones e implicaciones. In E. Agulló, J. L. Álvaro, A. Garrido, R. Medina \& I. Schweiger (Eds.), Nuevas formas de organización del trabajo y la empleabilidad. Oviedo: Universidad de Oviedo.

Blanch-Ribas, J. M. \& Stecher, A. (2009). La empresarización de servicios públicos y sus efectos colaterales. Implicaciones psicosociales de la colonización de universidades y hospitales por la cultura del nuevo 
capitalismo. In T. Wittke \& P. Melogno (Eds.), Psicología y organización del trabajo: producción de subjetividad en la organización del trabajo (pp. 191-209). Montevidéu: Psicolibros.

Boltanski, L. \& Chiapello, E. (1999). Le nouvel esprit du capitalisme. Paris: Gallimard.

Brasil (1988). Constituição da Republica Federativa do Brasil. Publicada no D. O. U. em 5 de outubro de 1988.

Brasil (1990). Lei Federal no 8.080, de 19 de setembro de 1990. Dispõe sobre as condições para a promoção, proteção e recuperação da saúde, a organização e o funcionamento dos serviços correspondentes e dá outras providências. Disponível na Internet: http://www.planalto.gov.br/ccivil_03/leis/18080.htm [6 julho 2011].

Brasil(2011). Portal da Saúde. Disponível na Internet: http://portal.saude.gov.br/portal/saude/cidadao/area.cfm? id_area $=1395$ [6 julho 2011].

Campos, G. W. S. (2006). Reflexões temáticas sobre equidade e saúde: o caso sus. Saúde e Sociedade, 15 (2), 23-33.

Cordeiro, H. (2004). O instituto de medicina social e a luta pela reforma sanitária: contribuição à história do SUS. Physis: Revista de Saúde Coletiva, 14 (2), 343-362.

Couto, A. L. (2009). Ideologia neoliberal e política social: a construção da resistência do SUS. Brasília: UnB.

Estado de São Paulo (2011). Secretaria da Saúde. Disponível na Internet: www.saude.sp.gov.br/content/ geral_acoes_oss.mmp [6 julho 2011].

Franco, T., Druck, G. \& Seligmann-Silva, E. (2010). As novas relações de trabalho, o desgaste mental do trabalhador e os transtornos mentais no trabalho precarizado. Revista Brasileira de Saúde Ocupacional, 35 (122), 229-248.

Gaulejac, V. (2007). Gestão como doença social. Aparecida, SP: Idéias e Letras.

Homedes, N. \& Ugalde, A. (2005). Las reformas de salud neoliberales en américa latina: una visión crítica a través de dos estudios de caso. Revista Panamericana de Salud Pública, 17 (3), 210-220.

Laurell, A. C. \& Noriega, M. (1989). Processo de produção e saúde: trabalho e desgaste operário. São Paulo: CebesHucitec.

Linhart, D. (2000). O indivíduo no centro da modernização das empresas: um reconhecimento esperado, mas perigoso. Trabalho E̊ Educação, 7, 24-36.

Linhart, D. (2009). Modernisation et précarisation de la vie au travail. Papeles del CEIC (Centro de Estudios sobre la Identidad Colectiva), Universidad del País Vasco, 43 (1), 1-19.

Martín-Baró, I. (2006). Hacia una psicología de la liberación. Revista Eletrónica de Intervención Psicosocial y Psicología Comunitaria, 1, 7-14.

Moreno, J. C., Pérez, E. \& Ruiz, P. (2004). El consenso de washington: aciertos, yerros y omisiones. Revista Perfiles Latinoamericanos, 25, 149-168.

Pereira, L. C. B. (1997). Estratégia e estrutura para um novo estado. Revista de Economia Política, 17 (3), 24-38.

Santos, N. R. dos (2008). Política pública de saúde no Brasil: encruzilhada, buscas e escolhas de rumos. Ciência $\mathfrak{E}$ Saúde Coletiva, 13 (suplemento), 2009-2018.

Sato, L. \& Bernardo, M. H. (2005). Saúde mental e trabalho: os problemas que persistem. Ciência e Saúde Coletiva, 10 (4), 869-878.

Seligmann-Silva, E. (2011). Trabalho e desgaste mental: o direito de ser dono de si mesmo. São Paulo: UFRJ/Cortez.

Sennett, R. (2006). La cultura del nuevo capitalismo. Barcelona: Anagrama.

\section{Endereço para correspondência}

marciahb@terra.com.br,

johannagarrido28@gmail.com,fverde@gmail.com

Recebido em: 18/06/2012

Revisado em: 15/12/2012

Aprovado em: 27/02/2012 